\title{
PRECISION CONTROL METHOD FOR PRE-STRESSING CONSTRUCTION OF SUSPEN-DOME STRUCTURES
}

\author{
Hongbo Liu ${ }^{1,2}$, Qinghua $\mathrm{Han}^{2}$, Zhihua Chen ${ }^{1,2}$, Xiaodun Wang ${ }^{2,}{ }^{*}$, Ren-Zhang Yan $^{2}$ and Bo Zhao ${ }^{2}$ \\ ${ }^{1}$ State Key Laboratory Of Hydraulic Engineering Simulation And Safety, Tianjin University, Tianjin 300072, China \\ ${ }^{2}$ Tianjin Key Laboratory of Civil Engineering Structure \& New Materials, Tianjin University, Tianjin 300072, China \\ *(Corresponding author: E-mail: maodun2004@126.com)
}

Received: 15 October 2012; Revised: 30 September 2013; Accepted: 19 December 2013

\begin{abstract}
A significant pre-stressing deviation from the pre-stressing target force is induced by the temperature change and sliding friction between hoop cables and cable-strut joints during the pre-stressing construction of suspen-dome structures. The deviation not only induces a considerable increase in member stress and nodal displacement but also reduces the load-bearing capacity of suspen-dome structures. To reduce this pre-stressing deviation, construction measures such as the use of a sufficient number of pre-stressing points, over pre-stressing construction, adoption of rolling cable-strut joints, and modification of the pre-stressing control value with temperature change were developed. A suspen-dome specimen with a diameter of $10.8 \mathrm{~m}$ was designed to clarify the aforementioned construction measures. Six schemes were designed and implemented based on this specimen. Finite element analysis was then conducted. Experimental and numerical results indicated that the construction measures presented in this paper could effectively reduce pre-stressing force deviation.
\end{abstract}

Keywords: Suspen-dome structures, Pre-stressing construction, Pre-stressing force deviation, Temperature change, sliding friction, Cable-strut joints, Experimental study, Numerical analysis

\section{INTRODUCTION}

A suspen-dome structure is a typical cable-strut structure that was first proposed by Kawaguchi [1]. A typical suspen-dome structure comprises an upper single-layer lattice shell and a low cable-strut system (Figure 1). The cable-strut system consists of hoop cables, radial cables, and struts. During the construction process, pre-stressing is introduced into the hoop cables to offset member stresses and nodal displacement under dead and live loads to increase the span of the suspen-dome structure. The suspen-dome structure has been widely applied in sports facilities and convention and exhibition centers in Japan and China [2-3].

Studies have been conducted to investigate the structural behavior of suspen-dome structures through both experimental and numerical analyses [4-19]. Previous research results provide many constructive suggestions and guidelines for the construction of suspen-dome structures. However, most studies have ignored the pre-stressing deviation induced by both temperature change and sliding friction between the hoop cables and cable-strut joints; pre-stressing deviations significantly affect the structural behavior of suspen-dome structures [4-5]. The aforementioned factors can increase the member stress and nodal displacement by $43.2 \%$ and $53.3 \%$, respectively, under dead and live loads based on previous studies [6-7]. 


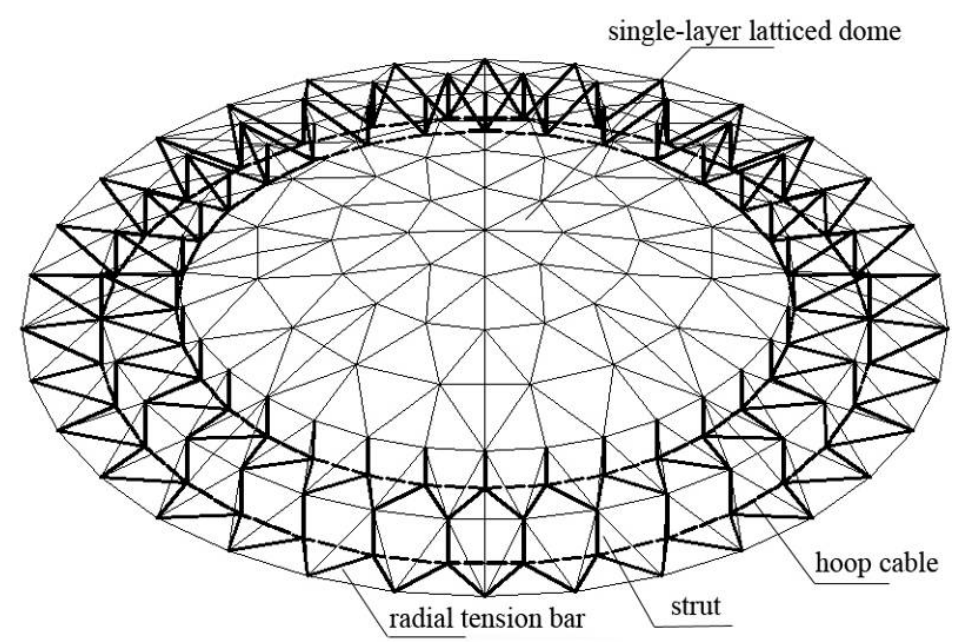

Figure 1. Structure Sketch Draw of Suspen-dome Structure

Therefore, this study aimed to find a solution for the aforementioned problems. Several construction measures were presented to reduce the effects of sliding friction and temperature change during construction. Thereafter, both numerical analysis and experimental study were conducted to verify the effects of construction measures on pre-stressing deviation reduction.

\section{CONSTRUCTION MEASURES}

Five construction measures, one of which simplifies the construction, are proposed in this section to reduce the pre-stressing deviation induced by sliding friction and temperature change during pre-stressing construction. These construction measures are described in detail as follows.

\subsection{Setting a Sufficient Number of Pre-stressing Points}

The pre-stressing deviation for each hoop decreases with increasing number of pre-stressing points. However, the construction cost will be high if the number of pre-stressing points is large. Therefore, an optimal number of pre-stressing points can obtain not only a low pre-stressing deviation but also an adequate construction cost.

Figure 2 shows that $n$ cable-strut joints are located between two pre-stressing points. $n$ can be either an odd (Figure 2(a)) or even number (Figure 2(b)). S-i denotes the $i$-th cable-strut joint, and C-i denotes the $i$-th hoop cable element (Figure 2).

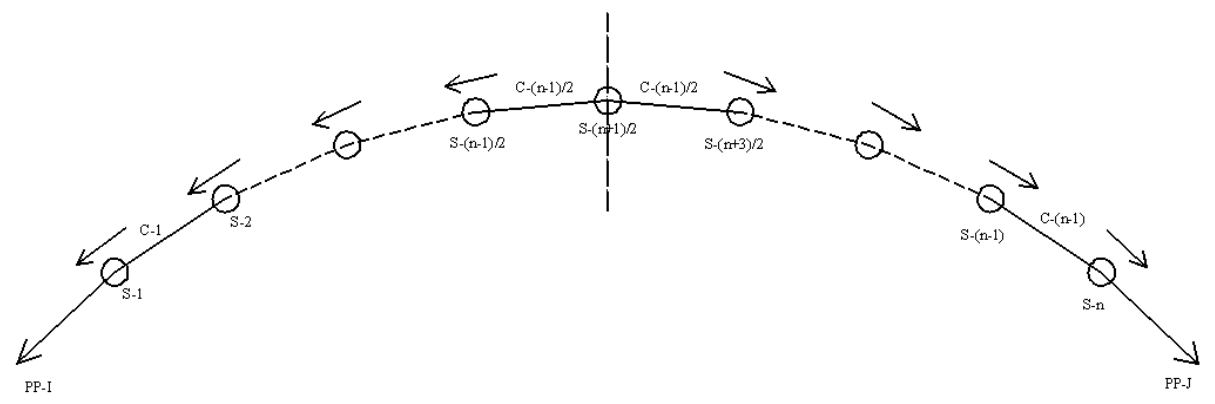

(a) Odd number of cable-strut joints 


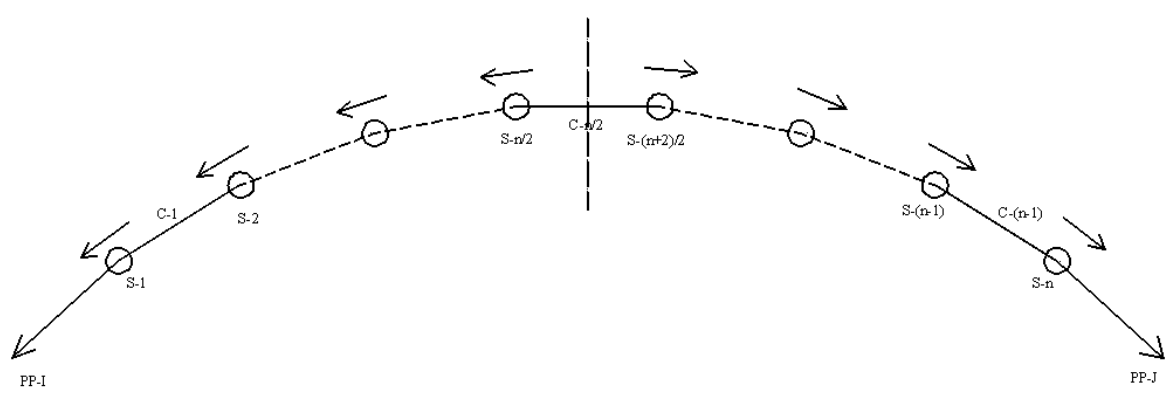

(b) Even number of cable-strut joints

Figure 2. Schematic of Cable Sliding between Two Pre-stressing Points

Figure 3 shows the tensions in the two hoop cables around a cable-strut joint with slip. The inertial effect of the joint is neglected. The relationship between the tensions at two sides on the slipping edge is expressed by Euler's equation:

$T_{2}=\alpha T_{1}$

where the tension ratio $\alpha$ is

$\alpha=e^{\mu \theta}$.

$\mu$ is the friction coefficient, and $\theta$ is the contact angle (Figure 3). Eq. 1 was applied to build the relationship between the tensions in the two adjacent hoop cable elements in suspen-dome structures.

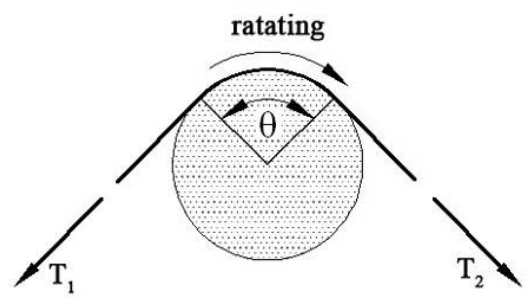

Figure 3. Hoop Cable Passing through a Cable-strut Joint

On the basis of the aforementioned mechanical principle and given that no other construction measures are implemented, the relationship between the maximum pre-stressing loss $\omega$ and number of cable-strut joints $n$ (Figure 2) can be expressed as follows:

$\omega=1-\frac{1}{\alpha^{\operatorname{nint(n/2)}}}$

The optimal number $n$ of cable-strut joints between two pre-stressing points was calculated by using Eq. 3. Furthermore, the optimal number of pre-stressing points could be obtained based on $n$.

\subsection{Over pre-stressing Construction}

During the pre-stressing construction of suspen-dome structures, over pre-stressing construction could reduce the pre-stressing loss induced by the sliding friction between the hoop cables and cable-strut joints. The best scheme for over pre-stressing construction included two steps. First, the 
pre-stressing construction was conducted by using a pre-stressing construction control value $T_{01}$ ( $T_{01}>T$, where $T$ denotes the design pre-stressing value). Second, the tensions at the pre-stressing points were relaxed to $T_{02}\left(T_{02}<T\right)$. The key point for this construction measure was to determine the values of $T_{01}$ and $T_{02}$ to minimize the pre-stressing deviation from the target value in the hoop cables.

In the first step, the tension force $T_{\min }$ of hoop cable element $S-(n-1) / 2$ (Figure $2(\mathrm{a})$ ) or $S-n / 2$ (Figure 2(b)) could be calculated by using the following equation:

$$
T_{\min }=T_{01} \frac{1}{\alpha^{\operatorname{nint}(n / 2)}} \text {. }
$$

In the second step, the sliding direction at the $m$-th cable-strut joint changed when the tensions at the pre-stressing points were relaxed to $T_{02}$ (Figure 4). Assuming that the tension of the $m$-th hoop cable element is $T_{m}$, the tension $T_{\text {mid }}$ of hoop cable element $S-(n-1) / 2$ (Figure 2(a)) or $S-n / 2$ (Figure 2(b)) could be calculated by Eq. 5. The tension $T_{02}$ at the pre-stressing point could be calculated as follows:

$$
\begin{aligned}
& T_{\text {mid }}=T_{\min }=T_{m} \frac{1}{\alpha^{\operatorname{nint}(n / 2)-\mathrm{m}}}, \\
& T_{02}=T_{m} \frac{1}{\alpha^{\mathrm{m}}},
\end{aligned}
$$

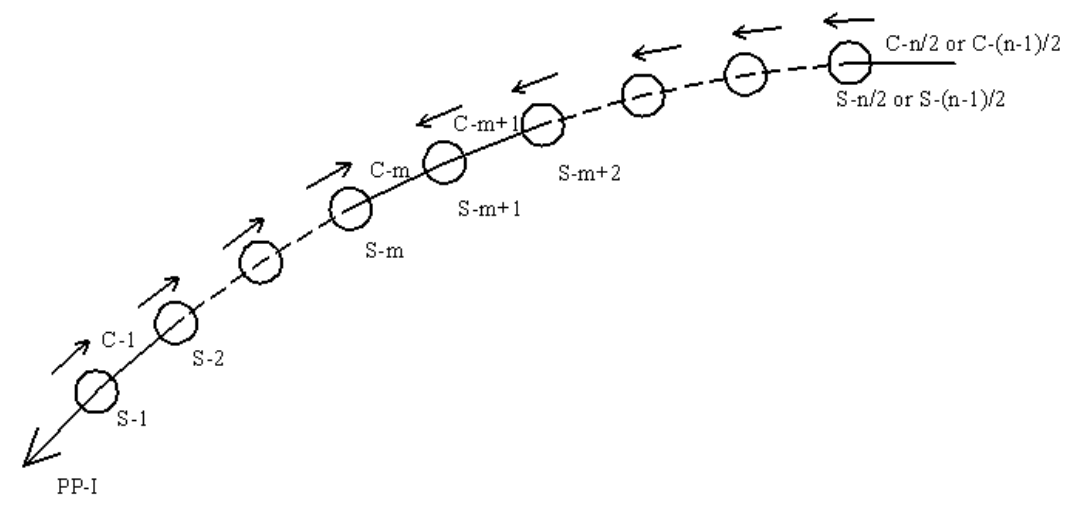

Figure 4. Schematic of Cable sliding in the Second Step

The error $\beta$ (calculated by Eq. 7) must be minimized to obtain a minimum deviation. On the basis of advanced mathematics theory, Eqs. 8 and 9 must be satisfied by minimizing $\beta$. Therefore, Eq. 8 was obtained. $m$ could be determined to be $\operatorname{nint}(n / 2) / 2$ by Eq. $8 . T_{m}$ could be calculated in Eq. 10 by Eq. 9 , and $T_{02}$ could be determined by Eq. 11. T01 could be determined in Eq. 12 by Eqs. 4 and 5.

$$
\begin{aligned}
& \beta=\max \left(T-T_{m i d}, T-T_{02}, T_{m}-T\right), \\
& T-T_{m} \frac{1}{\alpha^{\operatorname{nint}(n / 2)-\mathrm{m}}}=T-T_{m} \frac{1}{\alpha^{\mathrm{m}}}, \\
& T-T_{m} \frac{1}{\alpha^{\mathrm{m}}}=T_{m}-T,
\end{aligned}
$$




$$
\begin{aligned}
& T_{m}=\frac{2 T}{1+\frac{1}{\alpha^{m}},} \\
& T_{02}=\frac{2 T}{1+\alpha^{m}}, \\
& T_{01}=\frac{2 T}{1+\alpha^{m}} \times \alpha^{\operatorname{nin}(n / 2)} .
\end{aligned}
$$

\subsection{Adoption of Rolling Cable-strut Joints}

A continuous cable-strut joint has two types. One type is the sliding cable-strut joint, wherein cable forces are transferred by sliding around the joints. The other type is the rolling cable-strut joint, wherein cable forces are transferred by rolling around the joints [8-9]. Rolling friction is less than the sliding friction. Therefore, the rolling cable-strut joint was suggested for the pre-stressing construction of suspend-dome structures.

\subsection{Adjustment of Control Pre-stressing Value According to Temperature Change}

The temperature of suspen-dome structures changes significantly during construction because of the long pre-stressing construction period (e.g., one month) of large suspen-dome structures. Furthermore, the construction schedule might be arranged within a year. Therefore, the construction temperature will deviate from the design temperature during the pre-stressing construction. Consequently, the design pre-stressing had to be corrected based on the construction site temperature. Otherwise, the pre-stressing forces in the cables would significantly deviate from the target value. The corrected formula can be expressed as follows by using the linear assumption:

$$
T_{m i}=T_{i}-\left(t_{i}-t_{0}\right) T_{\text {ist }}^{\text {dome }}-\left(t_{i}-t_{0}\right) T_{\text {ist }}^{\text {cable }},
$$

where $T_{i}(i=1,2, \cdots, n)$ is the control value of the pre-stressing construction of the $i$-th hoop cable elements in suspen-dome structures. $T_{i}(i=1,2, \cdots, n)$ could be obtained by a tensile force compensation analysis without considering the temperature change during construction. $T_{i \Delta T}^{\text {dome }}(i=1,2 \cdots, n)$ is the variation value of the internal force for hoop cables and could be obtained by applying a temperature change with a value of $1{ }^{\circ} \mathrm{C}$ on the upper dome and strut members. $T_{i \Delta T}^{\text {cable }}(i=1,2 \cdots, n)$ is the variation value of the internal force for hoop cables and could be obtained by applying a temperature change with a value of $1{ }^{\circ} \mathrm{C}$ on the low cable element. $t_{0}$ is the design construction temperature, $t_{i}$ is the construction temperature when the $\underline{i}$-th hoop cables are pre-tensioned, and $T_{m i}$ is the control value of the pre-stressing construction for the $\underline{i}$-th hoop cables based on the temperature correction.

\subsection{Choosing the Proper Pre-stressing Time}

On the basis of the analysis and formula correction of the pre-stressing construction of suspen-dome structures, the pre-stressing cable force would be reduced if the temperature of the construction site was higher than the design temperature during pre-stressing construction. Therefore, the pre-stressing construction should be conducted at the hottest time during the construction period. 


\section{EXPERIMENTAL PROGRAM}

\subsection{Specimen Configuration}

A scaled specimen of a suspen-dome structure was designed and tested to verify the rationality of the construction measures presented in Section 2. Furthermore, the experiment results not only provided insights into the changes of hoop cable forces but also generated data to compare and verify the numerical results obtained by the method presented in Reference [12].

The span and height of this scaled specimen are 10.8 and $2.6 \mathrm{~m}$, respectively. The specimen consisted of a single-layer latticed shell (Figure 5) and one-loop cable-strut system (Figure 6). Four types of steel tubes, namely, $\phi 12 \times 3, \phi 14 \times 3, \phi 16 \times 3$, and $\phi 18 \times 3$, were adopted as the members of the single-layer lattice dome. The members are connected to each other by welded hollow spherical joints, which could be considered rigid joints. Steel tube $\phi 13 \times 3$ is adopted for the struts. The diameters of the hoop cables and radial steel bars are 12 and $11.5 \mathrm{~mm}$, respectively. Figure 7 shows that the entire scaled suspen-dome specimen was supported by 48 steel columns. The 48 steel columns were arranged in two rings.

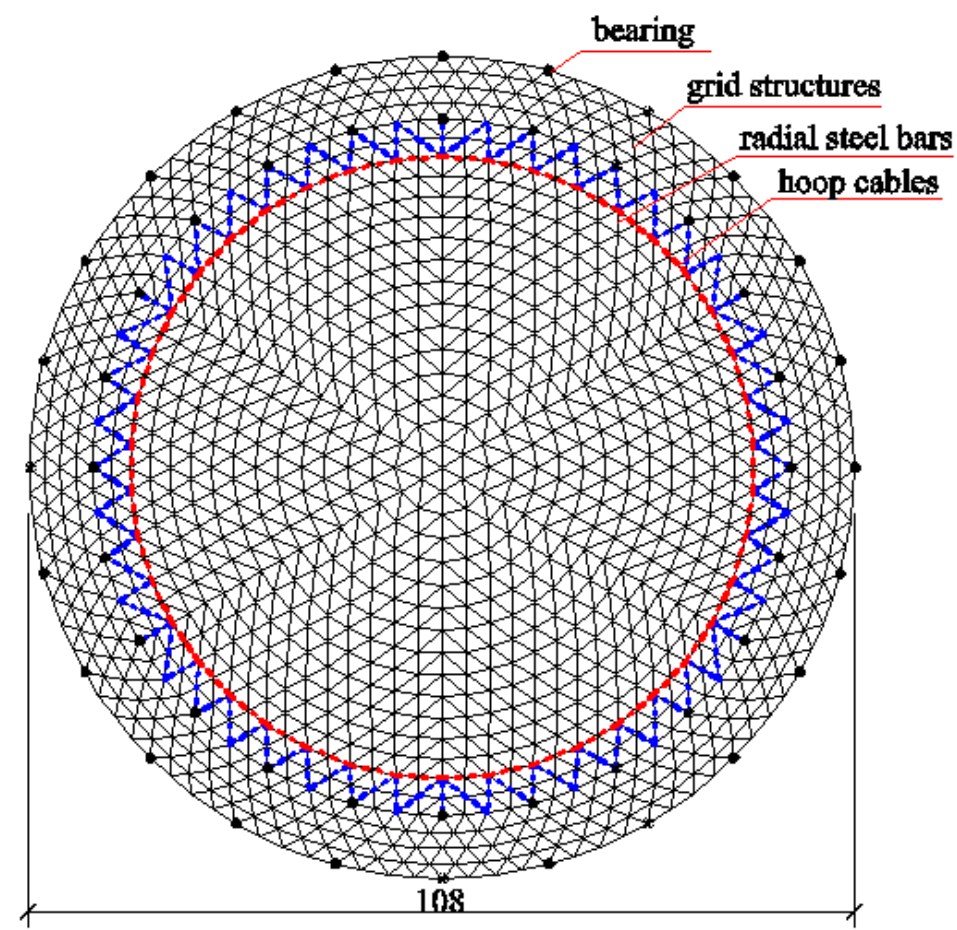

Figure 5. Top View of the Suspen-dome Structure

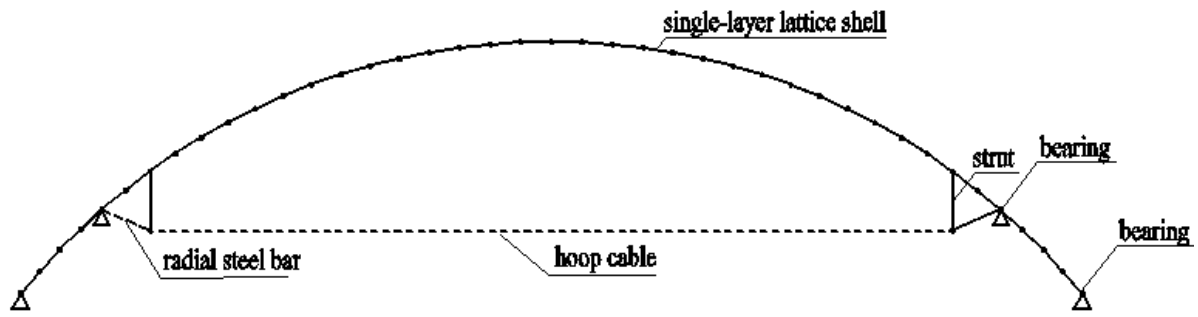

Figure 6. Sectional View of the Suspen-dome Structure 


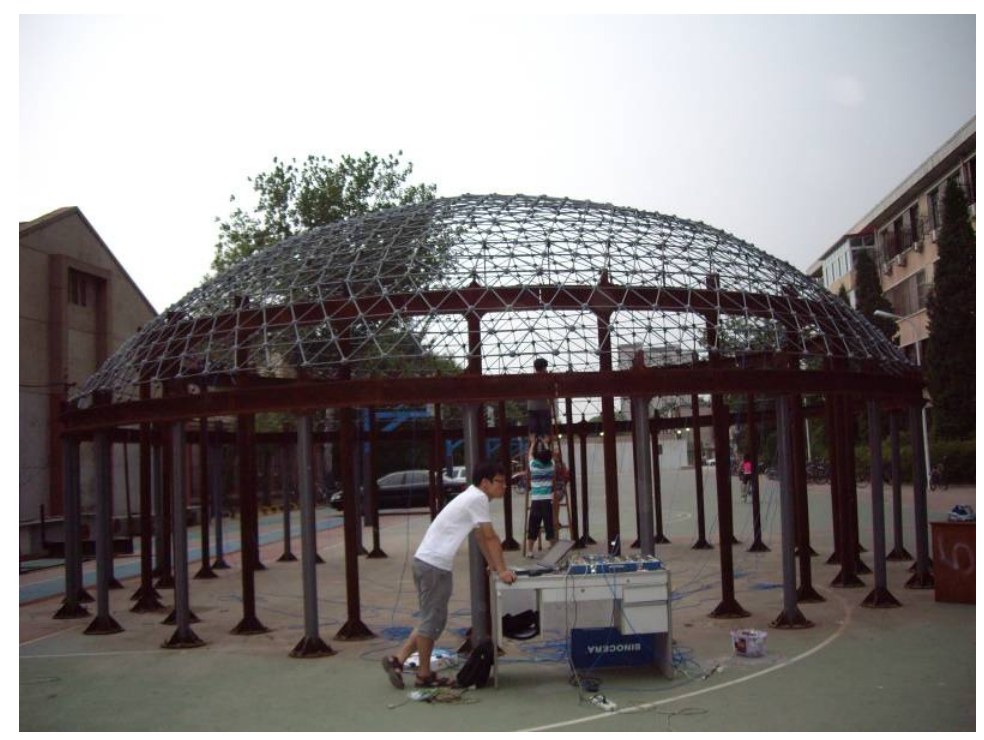

Figure 7. Tested Suspen-dome Model

A new cable-strut joint called the rolling cable-strut joint was adopted in the scaled specimen. Figures 8 and 9 show the assembly drawing and photo, respectively. Compared with the past continuous cable joint, the friction between the cable and joint was replaced with rolling friction because rolling friction was significantly smaller than the sliding friction. Therefore, this joint could reduce the pre-stressing loss induced by friction during pre-stressing construction.

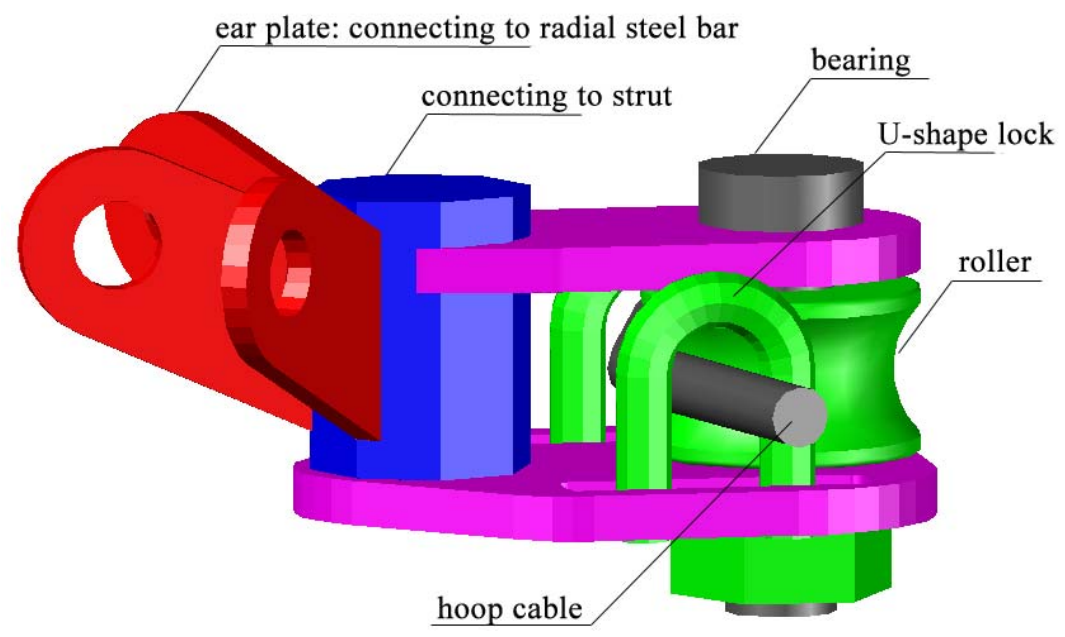

Figure 8. Assembly Drawing of the Rolling Cable-strut Joint 


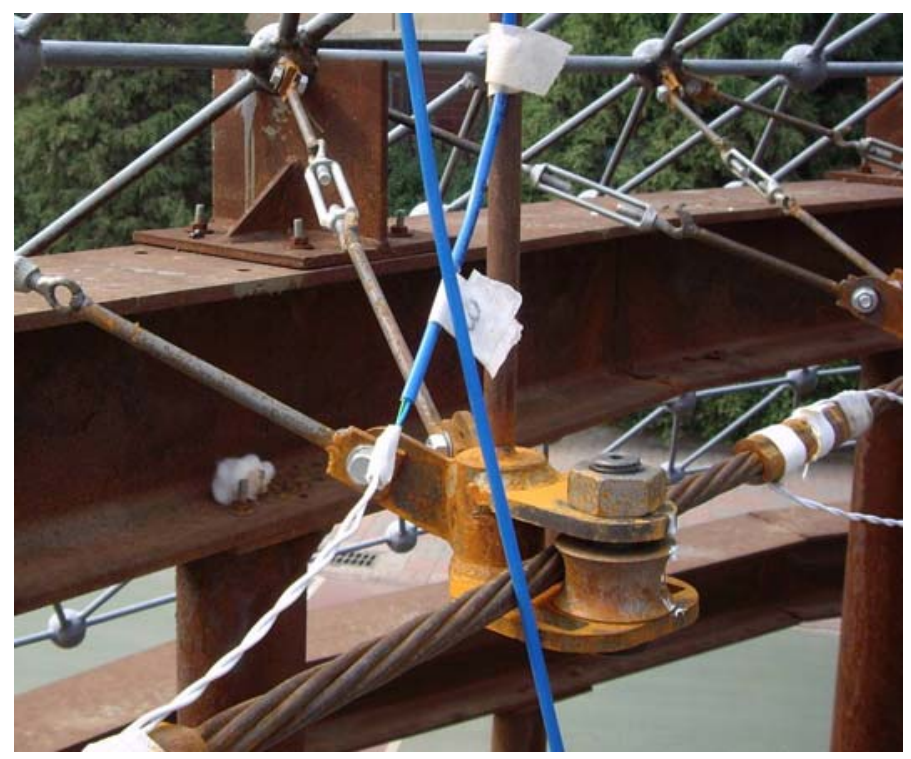

Figure 9. Photo of the Rolling Cable-strut Joint

In this specimen, screw bolts were used in the radial steel bars to adjust the length. The strain gauge could not be glued directly to the cable surface to measure the cable strain because of a large measurement error. In this test, the steel tubes were connected to the cables, and the strain gauge was glued to the steel tube surfaces to measure the cable strain (Figure 10). Figure 11 shows the tensioning device used in the experiment. For this device, tension was applied on the cable by bolt tightening.

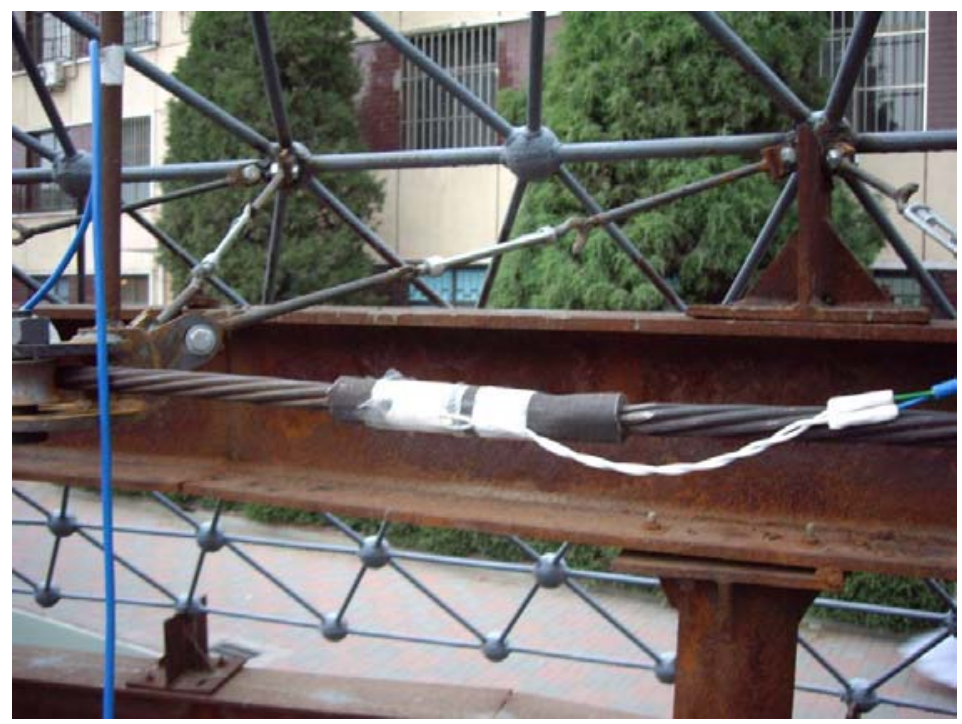

Figure 10. Steel Tube Connected in the Cables 


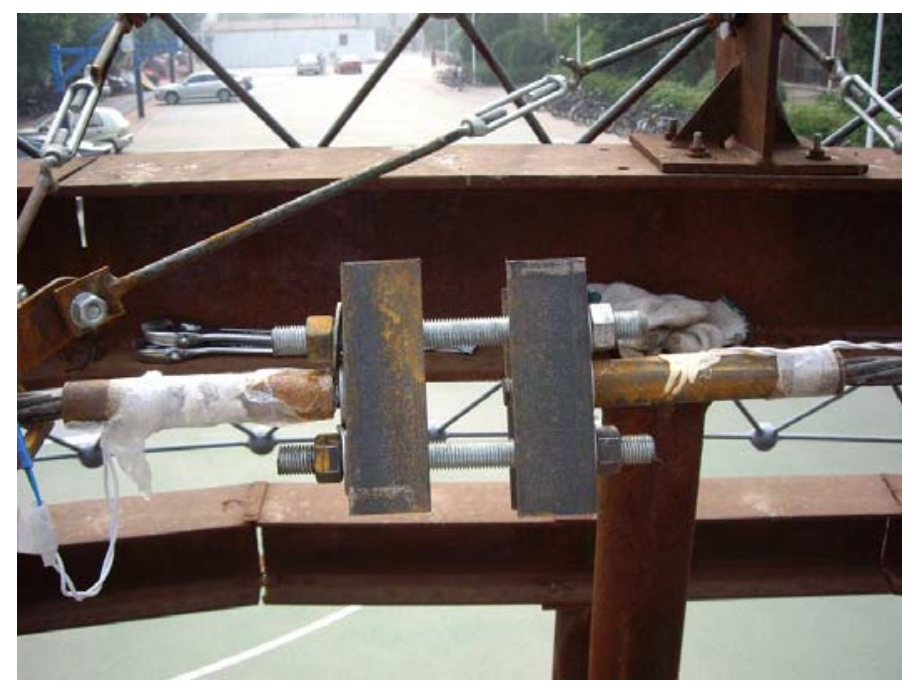

Figure 11. Tensioning Device used in the Experiment

\subsection{Experimental Scheme}

In this test, 4 tensioning devices were designed, and 16 steel tubes were included in the hoop cables. Figure 12 shows the number of tensioning devices and hoop cables, including steel tubes.

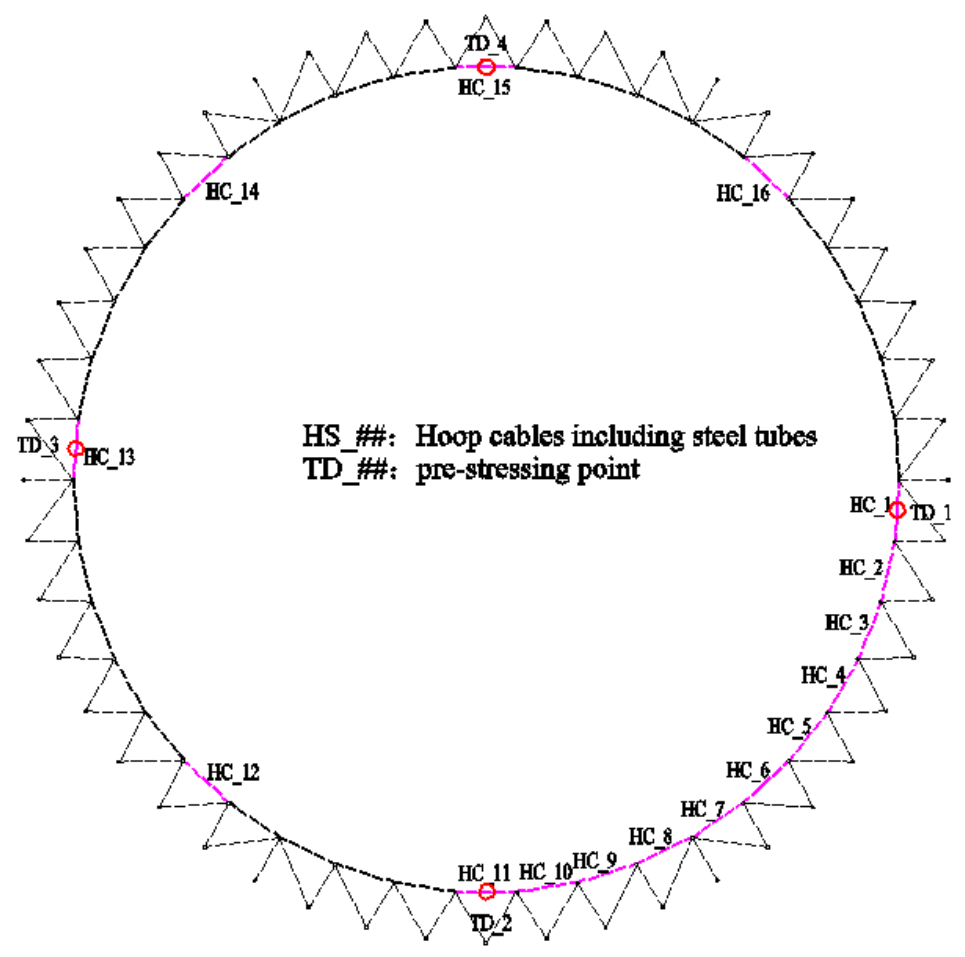

Figure 12. Arrangement of tensioning devices and hoop cables, including steel tubes

Six pre-stressing experimental schemes were designed through scheme optimization to verify the rationality of the five construction measures presented in Section 2. The detailed descriptions of the five schemes are as follows: 
Scheme 1: One tensioning device (TD-1) was used, and over pre-stressing construction was not considered. The pre-stressing control value was $10420 \mathrm{~N}$.

Scheme 2: Four pre-stressing points were used, and over pre-stressing construction was not considered. The pre-stressing control value was $10420 \mathrm{~N}$.

Scheme 3: Four pre-stressing points were used, and over pre-stressing construction was considered. The pre-stressing control values $T_{01}$ and $T_{02}$ for the first and second steps were 11532 and $10155 \mathrm{~N}$, respectively (Eqs. (11) and (12)).

Scheme 4: Four pre-stressing points were used, and over pre-stressing construction was not considered. The pre-stressing control value was $10420 \mathrm{~N}$, and the effect of daily temperature change was considered.

Scheme 5: Four pre-stressing points were used with the following assumptions: 1) the design temperature for pre-stressing construction was $\left.25.5^{\circ} \mathrm{C} ; 2\right)$ the practical pre-stressing temperature was $55.5^{\circ} \mathrm{C} ; 3$ ) the pre-stressing control value is $7520 \mathrm{~N}$ (Eq. (13)).

Scheme 6: Four pre-stressing points were used and both super-pre-stressing and temperature correction were considered. The following assumptions were made: 1) the design temperature for pre-stressing construction was $25.5^{\circ} \mathrm{C}$; 2) the practical pre-stressing temperature was $55.5^{\circ} \mathrm{C} ; 3$ ) the pre-stressing control values $T_{01}$ and $T_{02}$ for the first and second steps were 8631 and $7255 \mathrm{~N}$, respectively.

\subsection{Determination of the Friction Coefficient Value}

Three cases for the sliding cable-strut joint were tested to determine the friction coefficient value between the cables and cable-strut joints by $\mathrm{Wu}[20]$. The descriptions for the three cases are as follows:

Case 1: The roller axle and the roller were directly in contact with each other.

Case 2: Tetrafluoroethylene (Figure 13) was added between the roller axle and the roller.

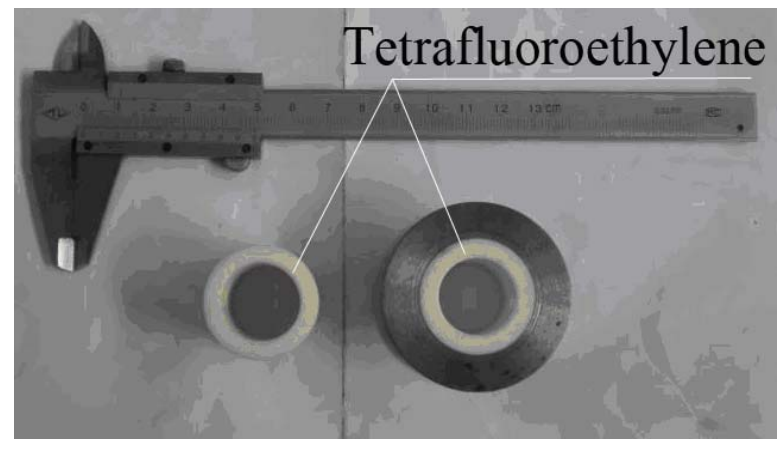

Figure 13. Tetrafluoroethylene was added in the Rolling Cable-strut Joint in Case 2

Case 3: The roller was welded to the joint body. Thus, the roller could not rotate around the roller axle, and the joint was equivalent to a traditional sliding cable-strut joint. 
A galvanized fiber-cored wire rope with a diameter of $14 \mathrm{~mm}$ was used as the cable in this test. The angle between the two cables at both ends of the cable-strut joint was $135^{\circ}$ (Figure 14). One side of the cable-strut joint was the loading end, and the other end was the fixed end. A hydraulic jack was adopted in this test to apply tension on the cables. The tension sensors were adopted to obtain the tension force on both sides of the cables.

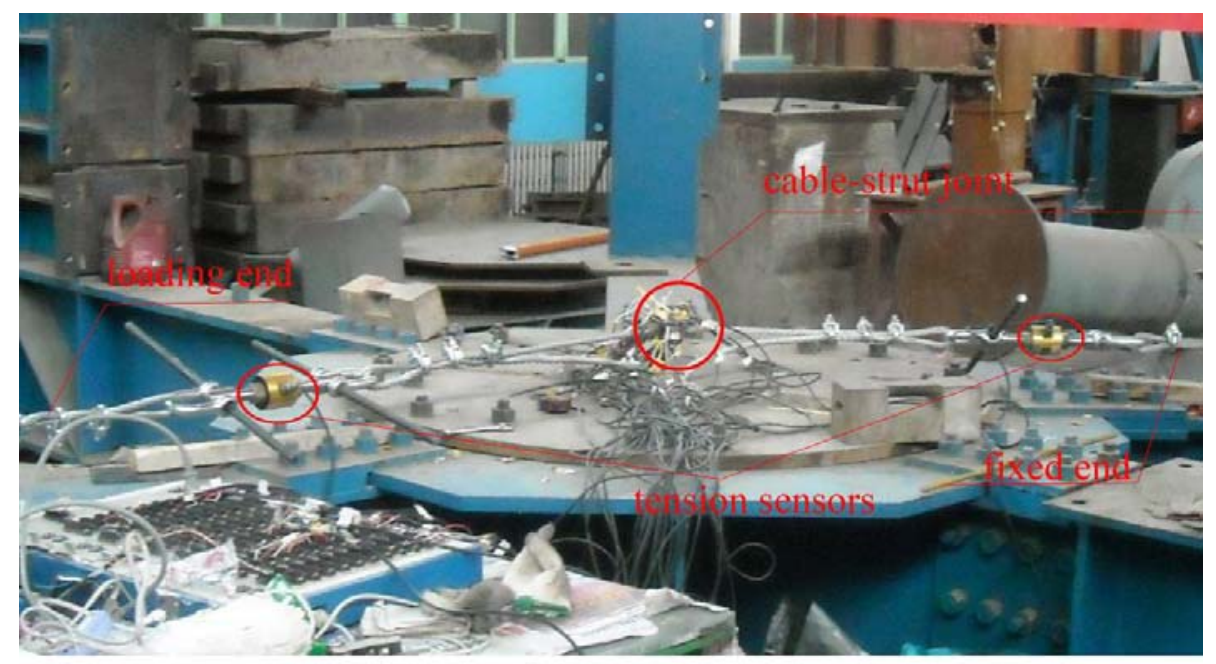

Figure 14. Test Plan

The mechanical equilibrium equation between the cable force $T_{1}$ of the fixed end and the cable force $T_{2}$ of the loading end could be written as follows:

$T_{2}=T_{1}+\left(T_{1}+T_{2}\right) \cos (\alpha / 2) \mu$

where $\alpha$ is the angle between the two cables at both sides of the cable-strut joints, and $\mu$ is the friction coefficient between the cables and cable-strut joint. In this equation, $\alpha, T_{1}$, and $T_{2}$ could be obtained in the test. Therefore, the friction coefficient ${ }^{\mu}$ could be calculated by the following equation:

$\mu=\frac{T_{2}-T_{1}}{\left(T_{1}+T_{2}\right) \cos (\alpha / 2)}$

Figure 15 shows the friction coefficient-cable force at the loading end curves for the three cases. The following conclusions were obtained based on Figure 15:

1) The friction coefficient of the rolling cable joint with Tetrafluoroethylene was the minimum friction coefficient.

2) The friction coefficient of the sliding cable joint was the maximum friction coefficient.

3) The overall friction coefficient increased with increasing cable forces. 


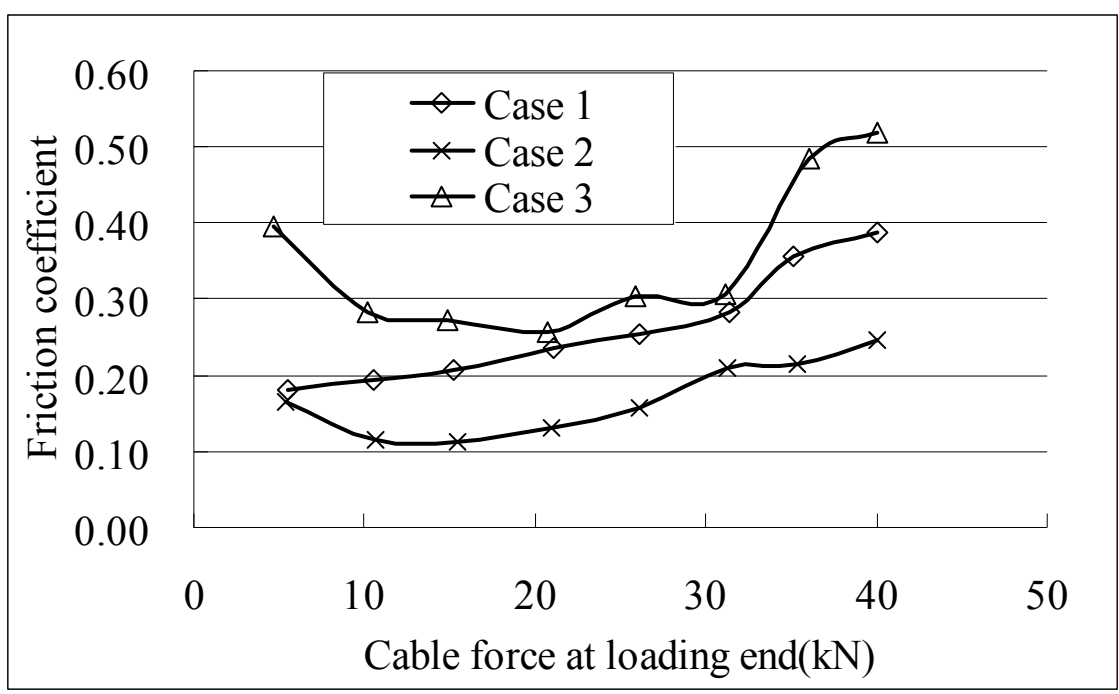

Figure 15. Friction Coefficient-cable Force at Loading End Curves

\section{NUMERICAL ANALYSIS}

To verify the cable-sliding criterion equation presented by author [12] and compare the results for the cable-strut joint with or without rollers, commercial finite element (FE) analysis software ANSYS was used to simulate the pre-stressing construction process of suspen-dome structures. The cable-sliding criterion equation [12], which is based on thermal expansion and contraction, is adopted to simulate cable sliding. This method required only a few APDL codes. The following presents the general procedure to simulate a pre-stressing construction that considers the sliding friction in ANSYS:

Step 1: An FE model was first established in ANSYS. Two-node LINK10 elements are adopted to simulate the hoop cable members; two-node LINK8 elements were then adopted to simulate the radial steel bars and strut members. A 3D beam element (BEAM188) was used to model members of the upper single-layer latticed shell, ring beams, and columns. The bottom of the columns was considered for pinning (Figure 16).

Step 2: Hoop cable pre-stressing were introduced by applying temperature load. A nonlinear FE analysis was then conducted to obtain the tensions of all hoop cable elements.

Step 3: If the tensions of both sides of the hoop cables of a cable-strut joint were not in equilibrium, the cable might slide around the joint. The sliding lengths around each joint could be obtained by solving the cable-sliding criterion equations [12]. On the basis of the sliding lengths around each joint, the virtual temperature of both sides of each joint could be evaluated by using the theory of thermal expansion and contraction. 


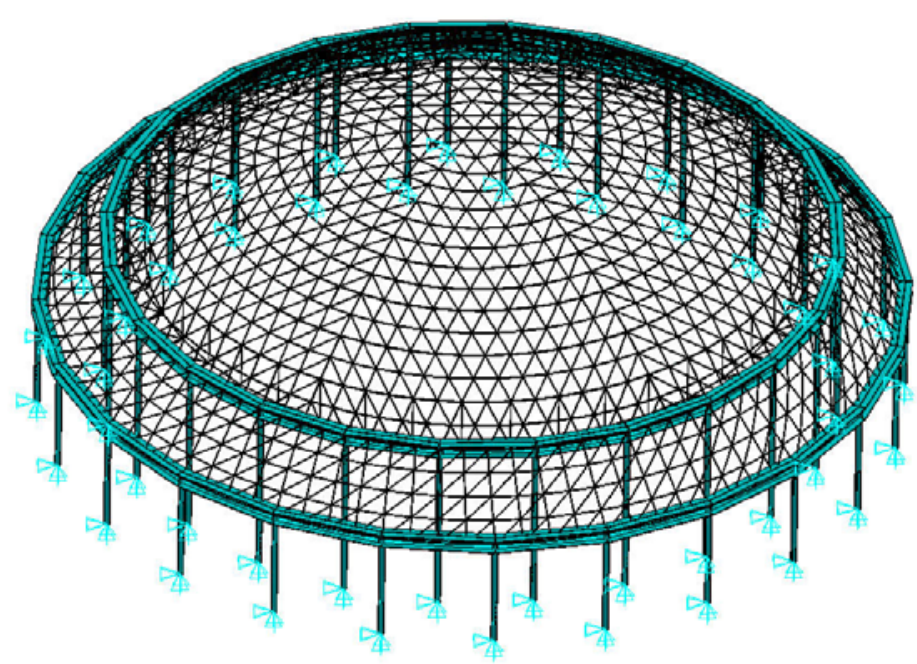

Figure 16. FE Model of the Tested Specimen

Step 4: A virtual temperature was then applied to the corresponding hoop cable elements. A re-analysis of the suspen-dome structure was conducted to obtain the tensions of all cable elements.

Step 5: Finally, the tensions of both sides of the cable-strut joint were verified. If the cable-strut joints were in equilibrium, the analysis was completed. Otherwise, Steps 3 to 5 were repeated until equilibrium was achieved.

\section{RESULTS ANALYSIS}

\subsection{Verification of the Numerical Analysis Method}

The maximum errors between the FE method and test results were calculated to verify the cable-sliding criterion equation presented in [12]. Table 1 shows the calculation results. The maximum error for Schemes 1 to 6 was $7.21 \%$. Therefore, the numerical method was reasonable and effective for simulating a construction process that considers the sliding friction.

Table 1. Maximum Error between the Numerical and Experimental Results

\begin{tabular}{|l|l|l|l|}
\hline Test NUM & Scheme 1 & Scheme 2 & Scheme 3 \\
\hline Maximum error & $7.21 \%$ & $3.88 \%$ & $3.30 \%$ \\
\hline Test NUM & Scheme 4 & Scheme 5 & Scheme 6 \\
\hline Maximum error & $5.62 \%$ & $3.30 \%$ & $3.26 \%$ \\
\hline
\end{tabular}

\subsection{Results of Schemes 1 to 3}

Figures 16(a) and 16(b) provides the states of tensioning device before and after pre-stressing construction under Scheme 1, respectively. These two figures verified that the tensioning device worked well in this experiment. Figures 17(a) and 17(b) presents the states of the rolling cable-strut joint before and after pre-stressing construction under Scheme 1, respectively. These two figures verified that the rolling cable-strut joint worked well in this experiment. 


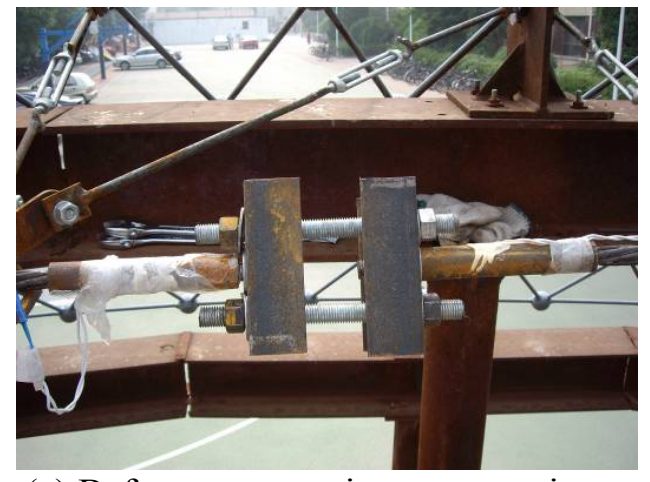

(a) Before pre-stressing construction

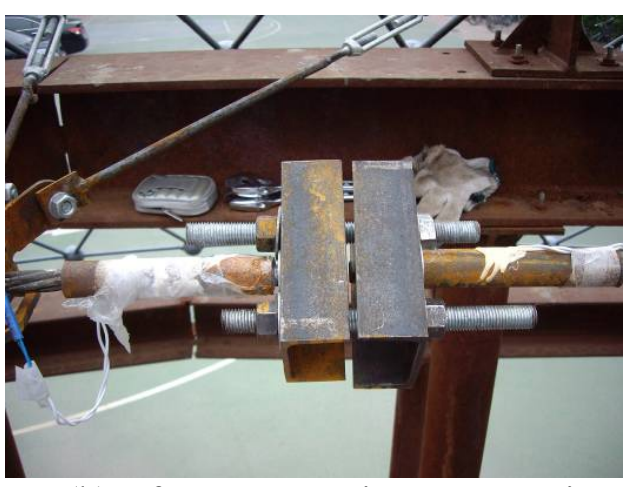

(b) After pre-stressing construction

Figure 16. States of the tensioning device before and after pre-stressing construction.

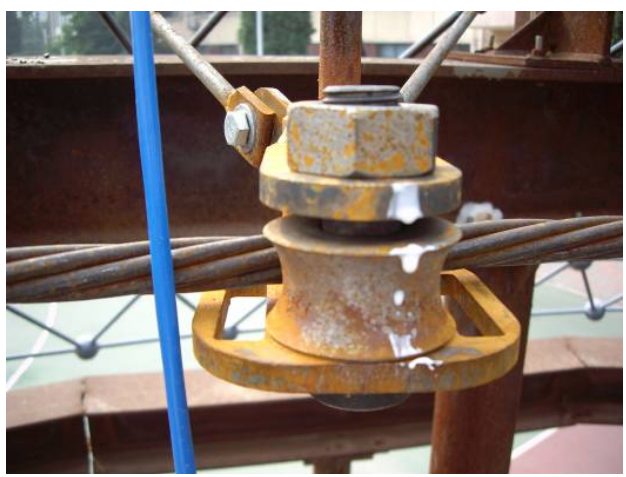

(a) Before pre-stressing construction

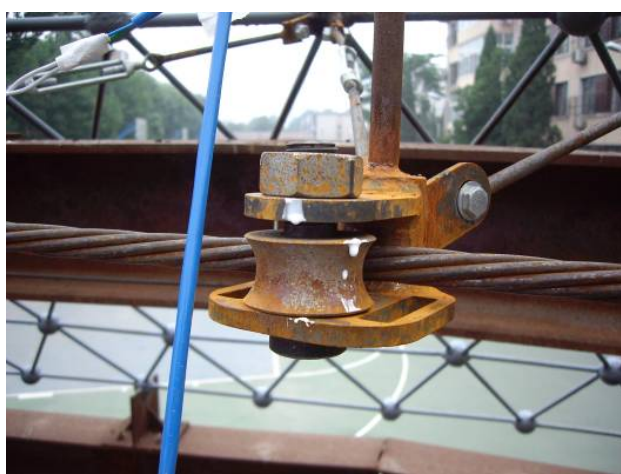

(b) After pre-stressing construction

Figure 17. States of the Rolling Cable-strut Joint before and after Pre-stressing Construction

Figures 18 to 24 show the theoretical and experimental results from Schemes 1 to 3 . The following conclusions were drawn based on the numerical and experimental results:

1) The maximum deviations from the design pre-stressing values for Schemes 1 and 2 were $55.46 \%$ and $20.90 \%$, respectively, when the sliding cable-strut joints were adopted. When the rolling cable-strut joint were adopted, the maximum deviations from the design pre-stressing values for Schemes 1 and 2 were $38.19 \%$ and $13.44 \%$, respectively. Compared with the sliding cable-strut joints, the maximum deviations for Schemes 1 and 2 were reduced by $31.14 \%$ and $35.69 \%$, respectively. The average pre-stressing losses of the cable-strut joint for Schemes 2 and 3 were $2.5 \%$ and $4.2 \%$, respectively. Therefore, the rolling cable-strut joint could effectively reduce the pre-stressing losses induced by friction.

2) The maximum deviations from the design pre-stressing values for Schemes 1 and 2 were $38.19 \%$ and $13.44 \%$, respectively. Therefore, increasing the pre-stressing points could effectively reduce the pre-stressing losses induced by friction.

3) The maximum deviations from the design pre-stressing values for Schemes 2 and 3 were $13.44 \%$ and $2.6 \%$, respectively. Therefore, super-tensioning could effectively reduce the pre-stressing losses induced by friction. 


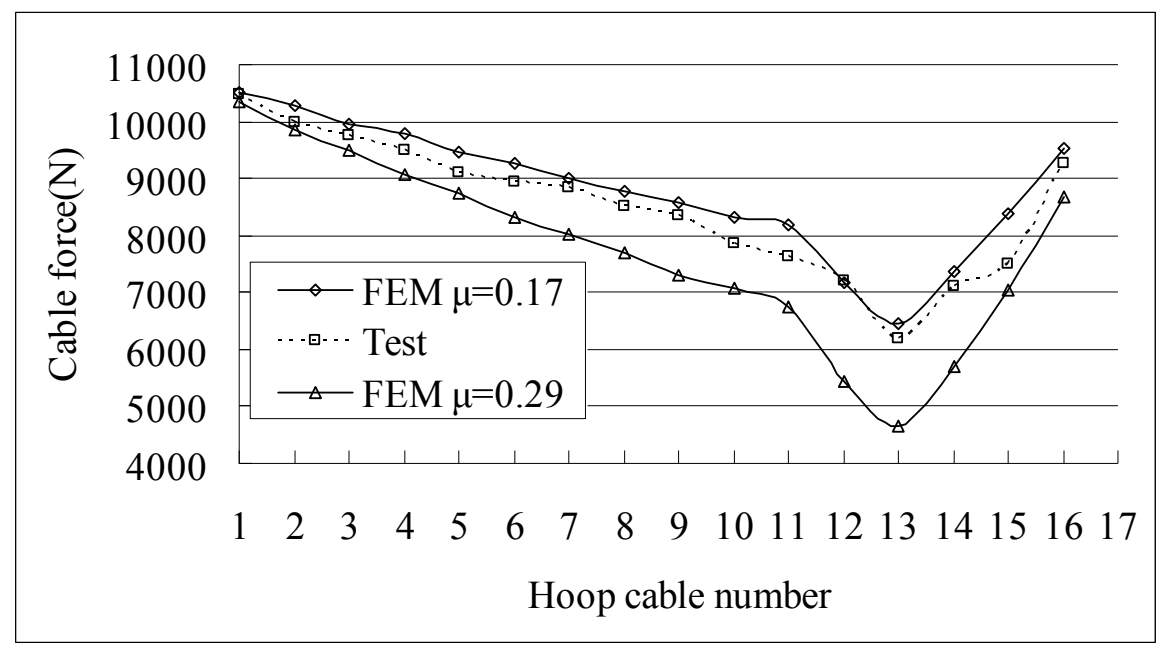

Figure 18. Hoop Cable Forces in Scheme 1

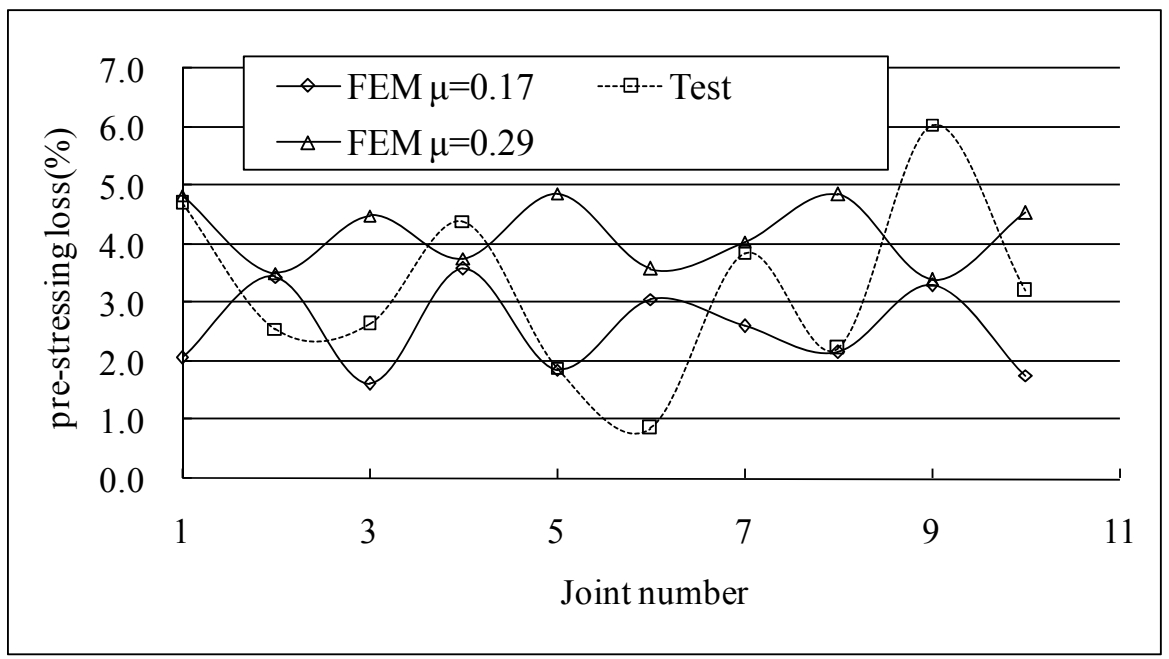

Figure 19. Pre-stressing Losses for the Cable-strut Joint in Scheme 1

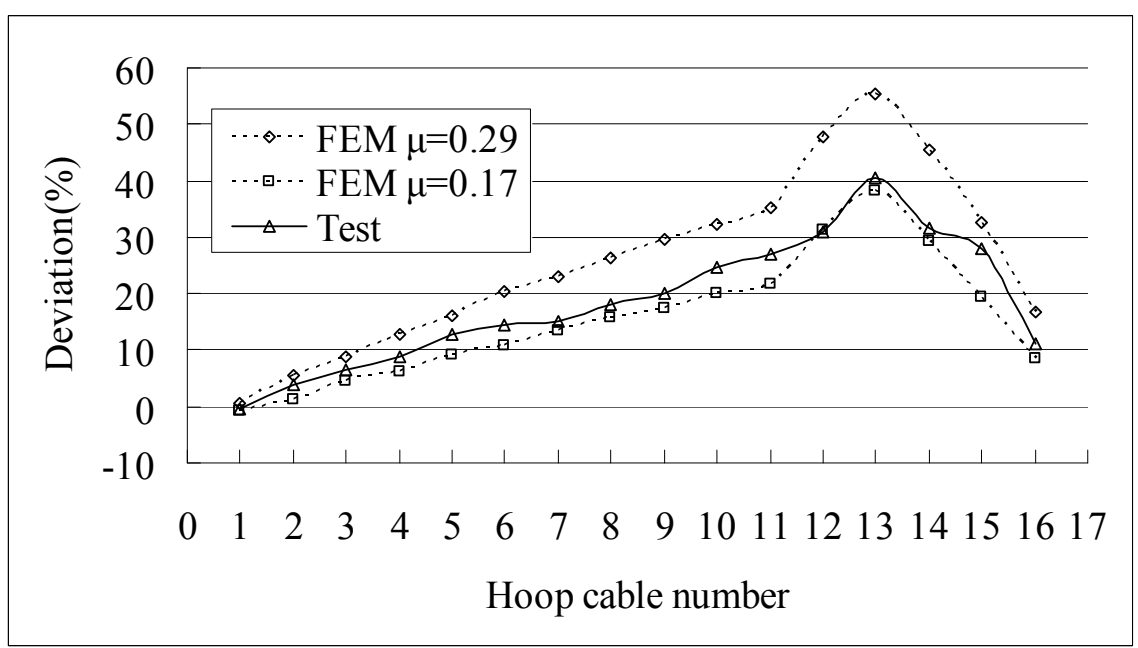

Figure 20. Deviations from the Design Pre-stressing Force in Scheme 1 


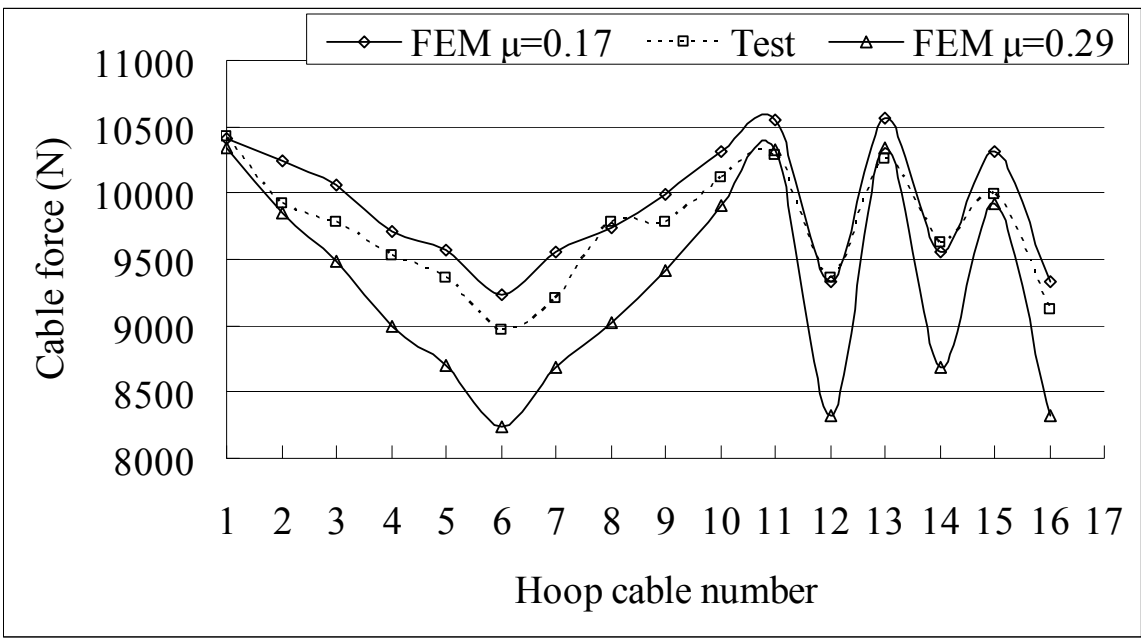

Figure 21. Hoop Cable Forces in Scheme 2

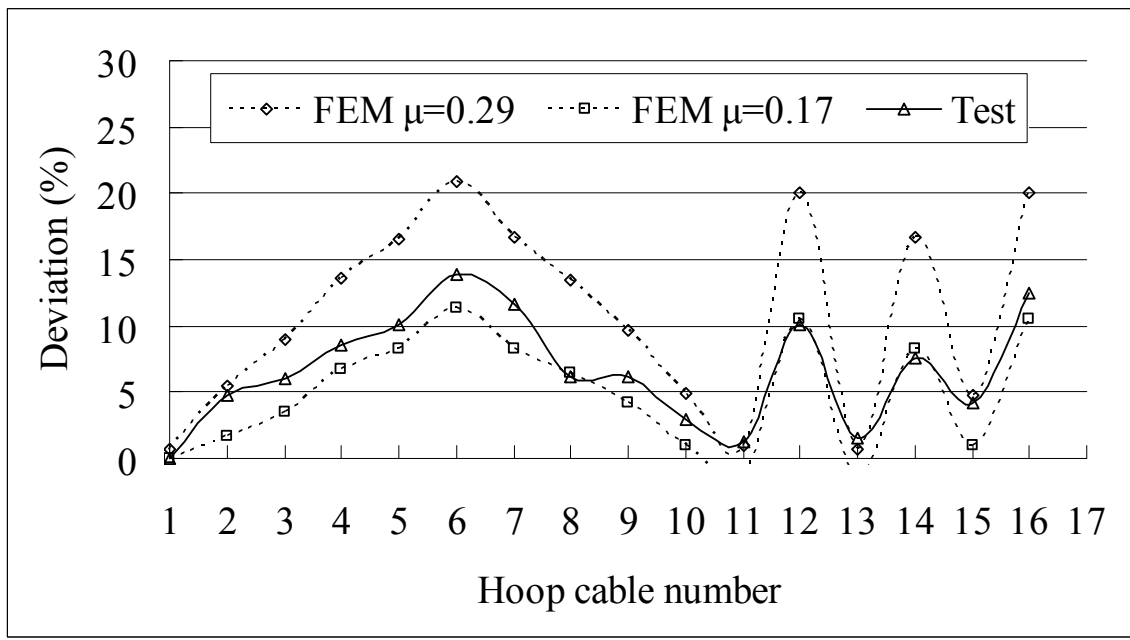

Figure 22. Deviations from the Design Pre-stressing Force in Scheme 2

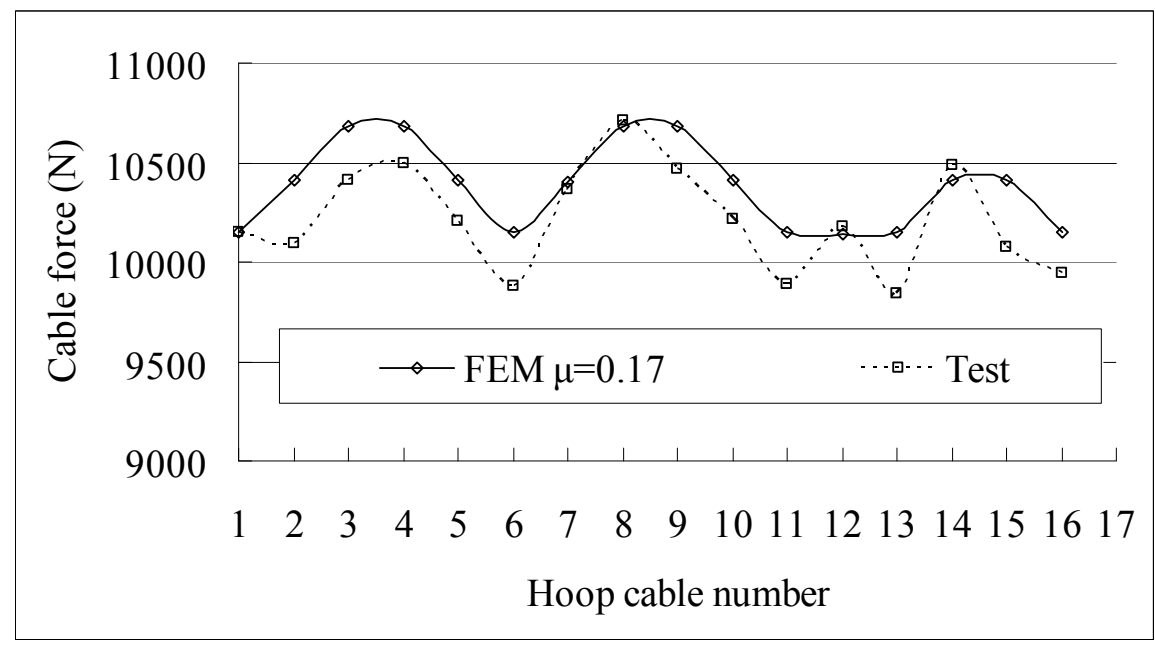

Figure 23. Hoop Cable Forces in Scheme 3 


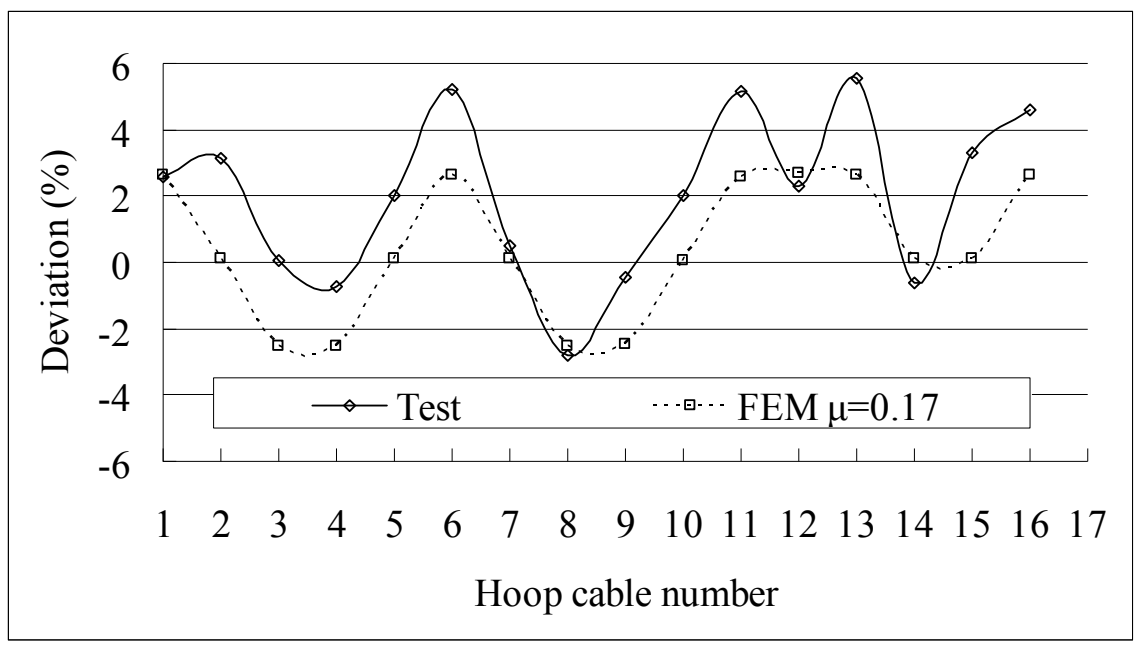

Figure 24. Deviations from the Design Pre-stressing Force in Scheme 3

\subsection{Results of Scheme 4}

Experimental Scheme 4 was conducted on 11 June 2011 to investigate the temperature change on the pre-stressing construction. The test specimen in this study was located outdoors and exposed to solar radiation. Therefore, the temperature of the tested model would significantly change under solar radiation during summer. The temperatures of steel tubes and cables were measured by using an infrared thermometer to provide temperature data for the numerical analysis. Ambient air temperature was also measured by using an air temperature gauge. Figure 25 shows the temperatures of the steel tube, cable, and air. The variation amplitudes of the ambient air temperature was $9^{\circ} \mathrm{C}$ from 8:30 to 19:00 (Figure 25). The variation amplitudes of the steel tube and cable were 22.81 and $20.4{ }^{\circ} \mathrm{C}$, respectively. Therefore, the temperature variation amplitude of the steel structure was significantly larger than that of the corresponding air temperature and solar radiation had a remarkable effect on steel temperature.

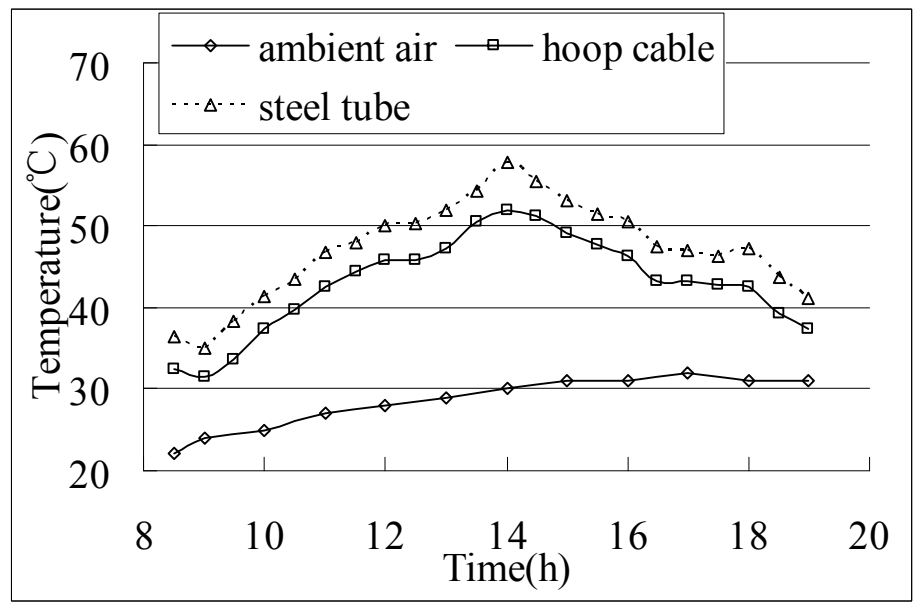

Figure 25. Temperatures of Steel Tube, Cable, and Air 
In Experimental Scheme 4, the pre-stressing construction was conducted at 8:27 by using four pre-stressing points. Figure 26 shows the hoop cable forces, which were measured every 10 min after the pre-stressing construction. Based on the temperature data, maximum temperature clearly occurred at approximately 14:00. Figures 27 and 28 show the hoop cable forces at 14:00 and 19:00, respectively. The hoop cable force distribution characteristics were similar at 8:27, 14:00, and 19:00. Therefore, the hoop cable force variations for all hoop cables were similar under temperature change that considers solar radiation.

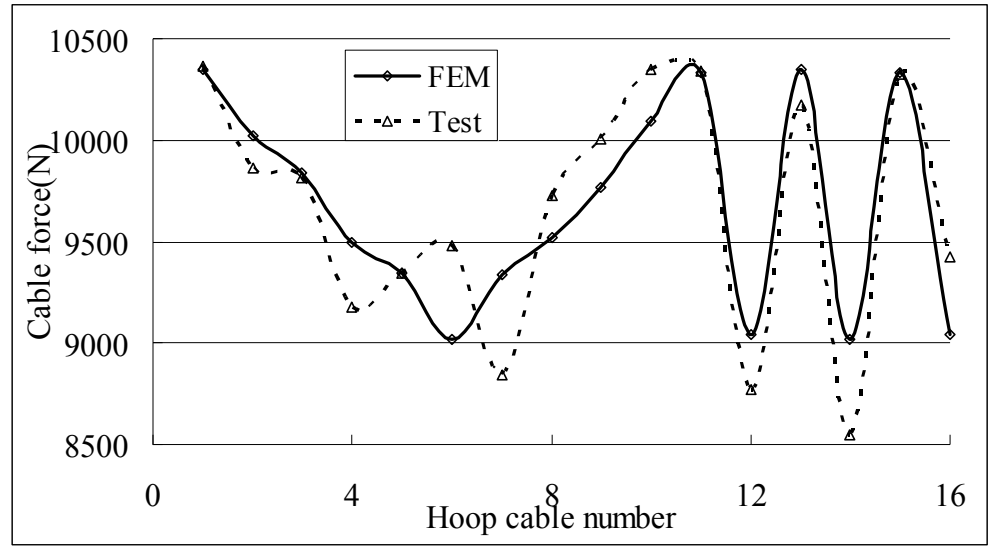

Figure 26. Hoop Cable Force at 8:27

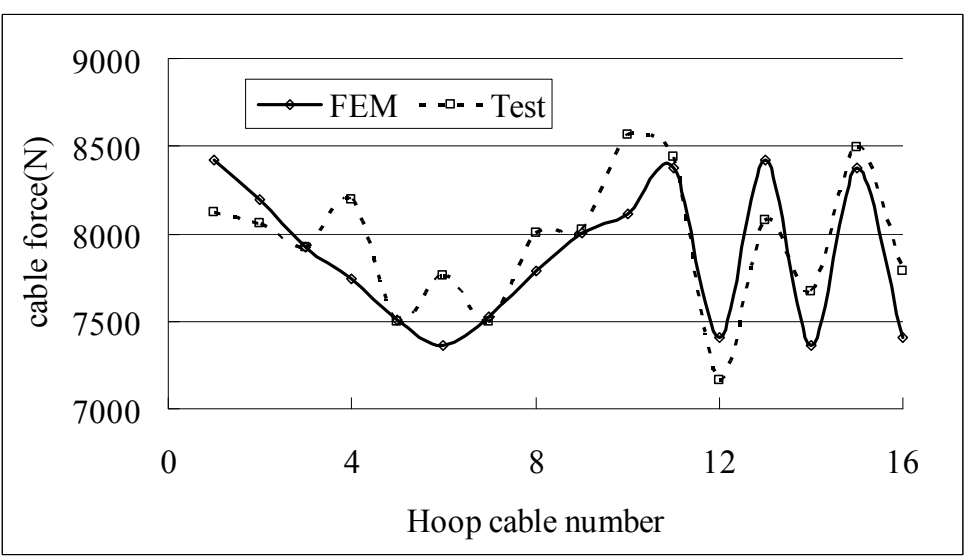

Figure 27. Hoop Cable Force at 14:00

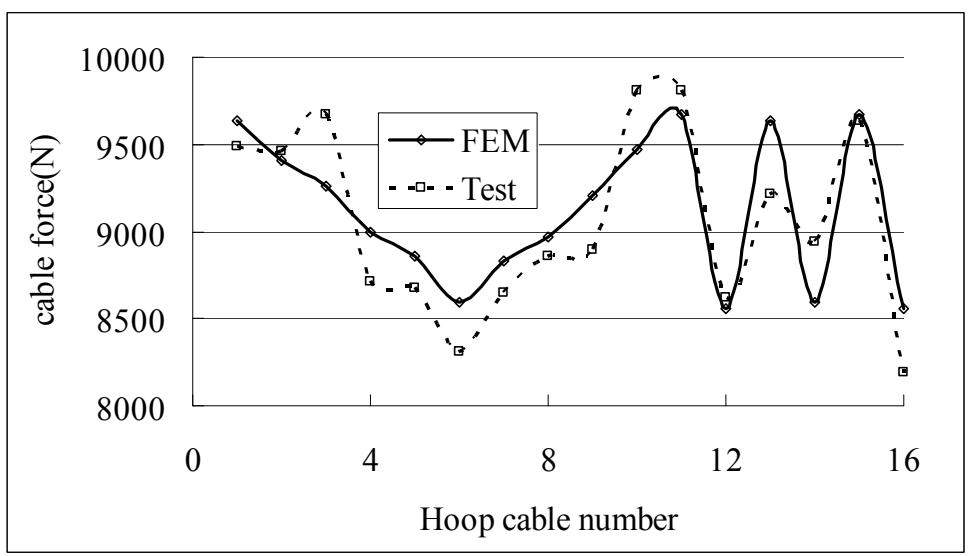

Figure 28. Hoop Cable Force at 19:00 
Figures 29 and 30 show the Cable Force-time Curves for Cable Elements 1 and 6, respectively. The hoop cable force clearly increased with decreasing structural temperature or vice versa. Compared with the hoop cable forces at 8:27, the cable forces at 14:00 for Cables 1 and 6 were reduced by $21.66 \%$ and $26.75 \%$, respectively. The aforementioned hoop cable force variations occurred within one day. The structural temperature variation during construction would be significantly larger considering the seasonal and weather changes (in terms of warm and cold current). Consequently, the hoop cable force variation would also be significantly larger. Therefore, the structural temperature change must be considered during construction.

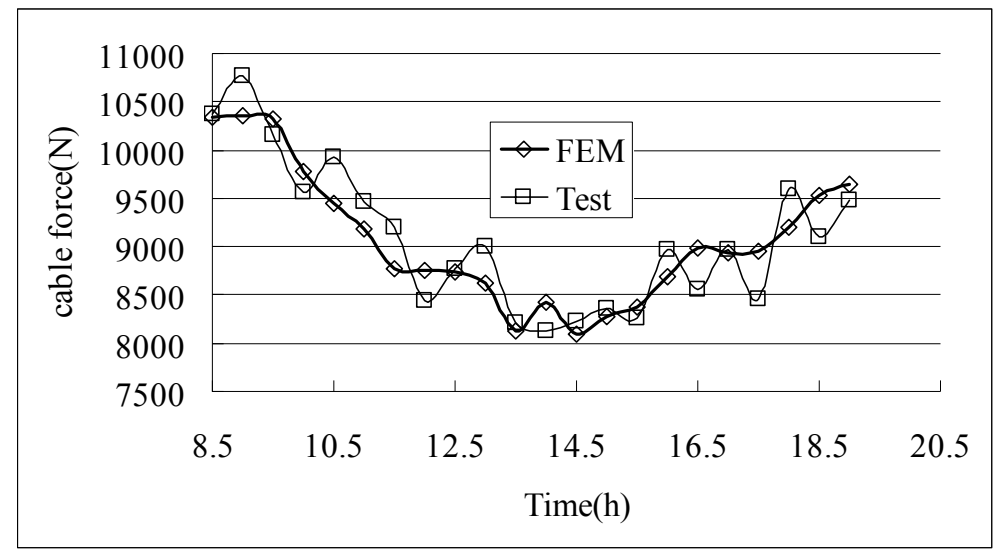

Figure 29. Cable Force-time Curve of Hoop Cable 1

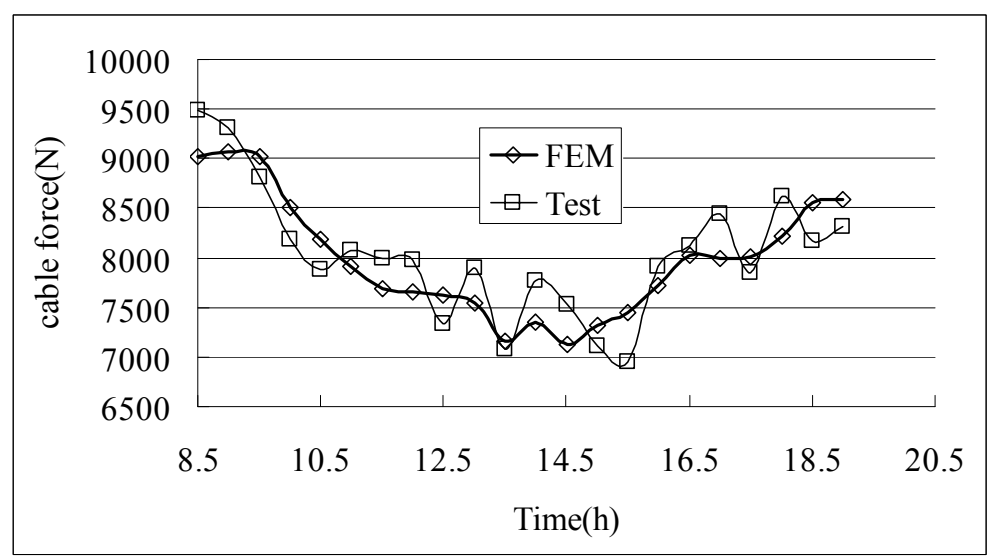

Figure 30. Cable Force-time Curve of Hoop Cable 6

\section{$5.4 \quad$ Results of Scheme 5}

Figure 31 shows the deviation from the design pre-stressing force in Scheme 5. Figure 31 shows that the maximum deviation from the design pre-stressing value for Scheme 5 was $11.37 \%$. Compared with that of Scheme 2, the modified calculation presented in this paper was clearly rational. 


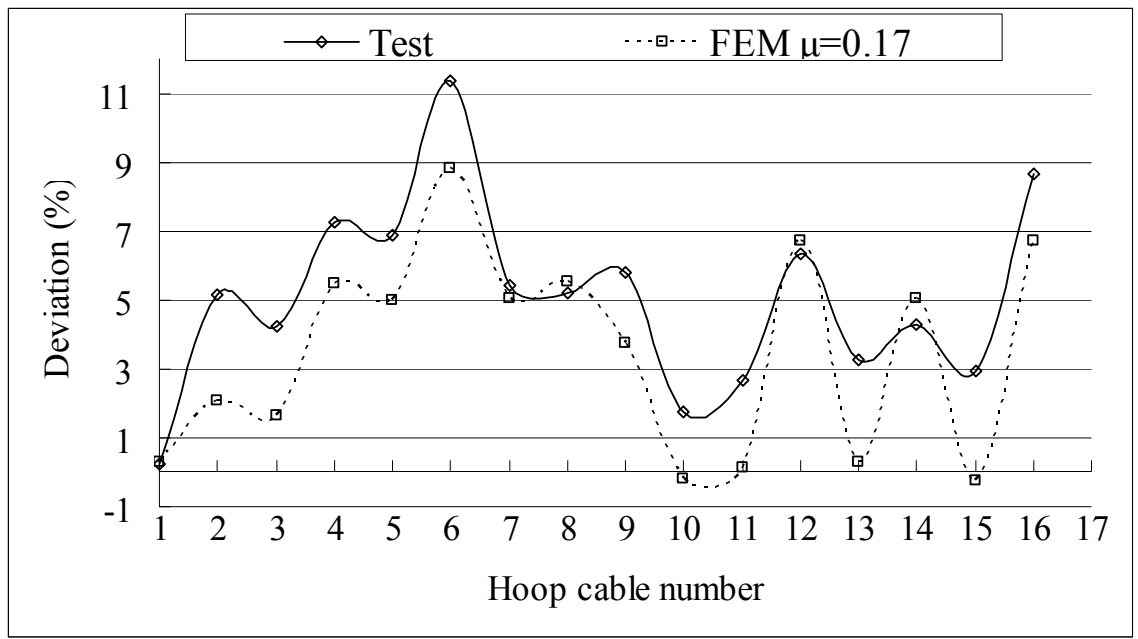

Figure 31. Deviation from the Design Pre-stressing Force in Scheme 5

\section{$5.6 \quad$ Results of Scheme 6}

Figure 32 shows the deviation from the design pre-stressing force in Scheme 6. Figure 32 shows that the maximum deviation from the design pre-stressing value for Scheme 6 was $5.77 \%$ by using both the temperature modified calculation and over pre-stressing construction measure. Therefore, the modified calculation presented in this paper was rational.

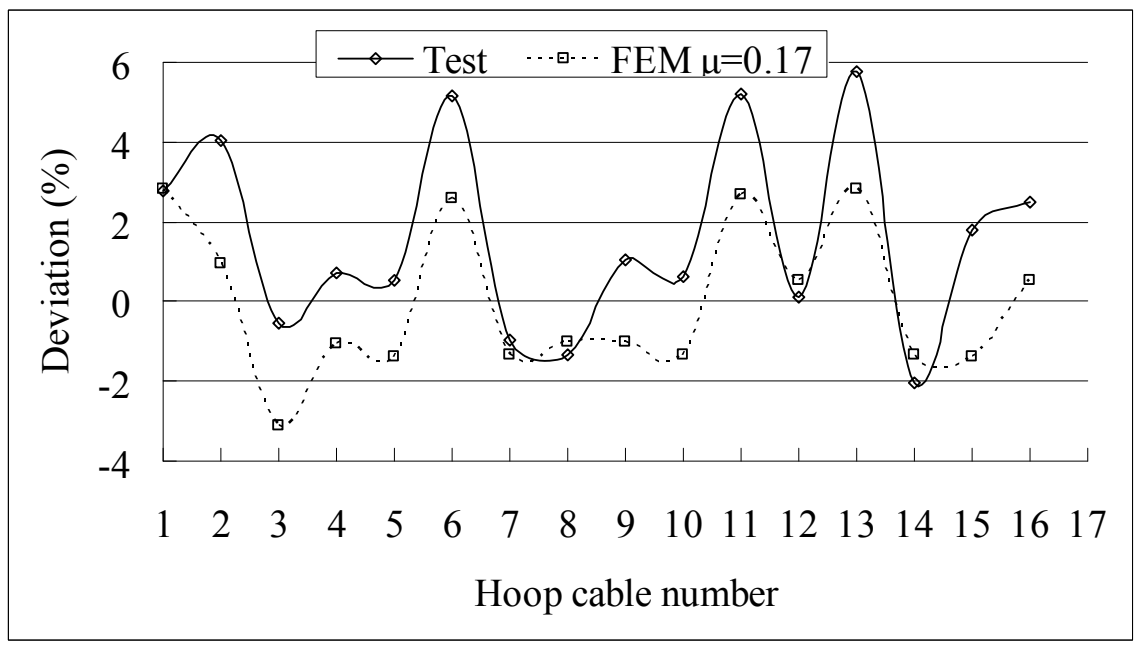

Figure 32. Deviation from the Design Pre-stressing Force in Scheme 6

\section{CONCLUSIONS}

This paper investigated the pre-stressing force deviation induced by sliding friction and temperature during pre-stressing construction. Five construction measurements were presented and verified by experimental study and numerical analysis to reduce the deviation and construction difficulty. The following conclusions were obtained based on the results of the experimental and numerical analysis: 
1) A remarkable pre-stressing deviation from the target value was induced by temperature change and the sliding friction between hoop cables and cable-strut joints.

2) Five advanced pre-stressing construction measurements were presented to reduce the pre-stressing deviation. These measurements included increasing the pre-stressing points, over pre-stressing the construction, adoption of rolling cable-strut joints, modification of the pre-stressing construction control value that consider temperature change, and selection of the hottest time for pre-stressing construction.

3) Several critical calculation formulas were derived for the over pre-stressing construction and the modification of the pre-stressing construction control value that considers temperature change during construction.

4) A suspen-dome specimen was designed and constructed. By using this specimen, six pre-stressing construction schemes were conducted to clarify five pre-stressing construction measures. A corresponding numerical analysis was also conducted.

5) The experimental and numerical results showed that the five construction measures could effectively reduce the pre-stressing deviation.

\section{ACKNOWLEDGEMENTS}

This work was supported by the National Natural Science Foundation of China (No. 51208355), China Postdoctoral Science Foundation Funded Project (No. 2012M510751 and 2013T60253), and Tianjin Natural Science Foundation(11JCZDJC24000).

\section{REFERENCES}

[1] Mamoru Kawaguchi, Masaru Abe and Ikuo Tatemichi, "Design, Tests and Realization of 'suspen-dome' System", Journal of the IAAS, 1999, Vol. 40, No. 131, pp. 179-192.

[2] Chen, Z.H., Liu, H.B. and Niu, B., "Application of Suspen-dome Structures in Engineering", Industrial Construction, 2010, Vol. 40, No. 8, pp. 42-48. (In Chinese)

[3] Zhang, Z.H., Cao, Q.S., Dong, S.L. and Fu, X.Y., "Structural Design of a Practical Suspendome", Advanced Steel Construction, 2008, Vol. 4, No. 4, pp. 323-340.

[4] Liu, H.B., Chen, Z.H. and Zhou, T., "Pre-stress Loss induced by Friction in Suspen-dome Construction", Journal of Tianjin University, 2009, Vol. 42, No. 12, pp.1055-1060. (In Chinese)

[5] Liu, H.B., Chen, Z.H. and Zhou, T., "Research on the Process of Pre-stressing Construction of Suspen-dome Considering Temperature Effect", Advances in Structural Engineering, 2013, Vol. 16, No. 6, pp. 1001-1009.

[6] Liu, H.B. and Chen, Z.H., "Research on the Effect of Construction Process on the Structural Behavior of Suspen-dome Structures", Advanced Steel Construction (accepted)

[7] Wang, Y.Q., Guo, Z.X., Wang, Y.F., et al., "Structural Performance Analysis of Long Span Suspen-dome Considering Construction Factors", Building Structures, 2010, Vol. 40, No. 2, pp. 59-62. (In Chinese)

[8] Cui, X.Q. and Guo, Y.L., "Influence of Gliding Cable Joint on Mechanical Behavior of Suspend-dome Structures", J. International Journal of Space Structures, 2004, Vol. 19, No. 3 , pp. 149-154. 
[9] Chen, Z.H. and Wu, Y.J., "Design of Roll Cable-strut Joint in Suspen-dome and Analysis of its Application in Whole Structure System", J. Journal of Building Structures, 2010, Supplementary Issue 1, pp. 234-240. (In Chinese)

[10] Wang, S., Zhang, G.J., Zhang, A.L., et al., "The Prestress Loss Analysis of Cable-strut Joint of the Badminton Gymnasium for 2008 Olympic Games", J. Journal of Building Structures, 2007, Vol. 28, No. 6, pp. 39-44. (In Chinese)

[11] Zhang, G.F., Dong, S.L., et al., "Research on Sliding Cable in Construction of Suspend-dome Structures", J. Journal of Zhejiang University, 2008; Vol. 42, No. 6, pp.1051-1057. (In Chinese)

[12] Liu, H.B., Chen, Z.H., Wang, X.D. and Zhou, T., "Establishing and Application of Cable-sliding Criterion Equation”, J. Advanced Steel Construction, 2011, Vol. 7, No. 2, pp. 131-143.

[13] Kitipornchai, S., Kang, W.J., Lam, H.F., et al., "Factors Affecting the Design and Construction of Lamella Suspen-dome Systems", J. Journal of Constructional Steel Research, 2005, Vol. 61, No. 6, 764-785.

[14] Kang, W.J., Chen, Z.H., Lam, H.F., et al, "Analysis and Design of the General and Outmost-ring Stiffed Suspen-dome Structures”, J. Engineering Structures, 2003, Vol. 25, No. 13, pp. 1685-1695.

[15] Cao, Q.S. and Zhang, Z.H., "A Simplified Strategy for Force Finding Analysis of Suspendomes”, J. Engineering Structures, 2010, Vol. 32, No. 1, pp. 306-310.

[16] Liu, H.J., Luo, Y.F. and Yang, L.F., "Construction Parameters and Process Simulation Method of Suspen-domes", J. Journal of Civil, Architectural \& Environmental Engineering, 2010, Vol. 32, No. 5, pp. 142-148. (In Chinese)

[17] Zhang, A.L., Liu, X.C., Wang, D.M., et al., "Static Experimental Study on the Model of the Suspend-dome of the Badminton Gymnasium for 2008 Olympic Games", Journal of Building Structures, 2007, Vol. 28, No. 6, pp. 58-67. (In Chinese)

[18] Li, K.N. and Huang, D.H., "Static Behavior of Kiewitt6 Suspendome" J. Structural Engineering and Mechanics, 2011, Vol. 37, No. 3, pp. 309-320.

[19] Liu, H.B. and Chen, Z.H., "Structural Behavior of the Suspen-dome Structures and the Cable Dome Structures with Sliding Cable Joints", J. Structural Engineering and Mechanics, 2012, Vol. 43, No. 1, pp. 53-70.

[20] Wu, Y.J., “Analysis of Sliding Cable Element and Node”, D. Tianjin, Tianjin University, 2010. 